\title{
THE EXPLANATION OF THE INDICES AND COMPONENTS OF THE CAFE IN THE TRADITIONAL AND MODERN TIMES OF IRAN
}

\author{
Farshad Hatami*, Avideh Talaei \\ Department of Art and Architecture, Islamic Azad University Tehran-West Branch, Iran \\ E-mail: project_hatami@yahoo.com*,Depart_talaei@yahoo.com \\ Received: March 16, 2021 / Revised: August 27, 2021 | Accepted: September 6, 2021 \\ DOI: https://doi.org/10.36782/ijsr.v3i2.76
}

\begin{abstract}
Several factors affecting the cultural growth of the society are the correct function of social interaction, daily activities in the workplace, and increasing social action according to population growth rate need to be more evident. Review of past history showed the arrival of cafe culture in the Safavidi era and Shah Abbas(I)ii and establishment of coffee houses in Qajariii and Pahlavi era with social, economic and cultural function. In the first Pahlavi period, with the arrival of a new style of cafe from the west, the social approach and architectural style of the coffee house changed to a coffee shop. The young people of the society, as the audience, chose the coffee shop as a platform for social communication. In this article, we try to explain the course of physical and cultural developments of cafes and increase the benefit of young people from temporary urban social exchange centres as a third place (home, workplace and coffee shop) by interpreting the study examples of traditional and modern cafes in the period. We will pay attention to the Pahlavi, contemporary and modern West.
\end{abstract}

Keywords: Architectural Space, Coffee Shop, Hominess, Social Index, Social Interaction.

\section{INTRODUCTION}

Among the classes and classes of modern times from the peasant, the worker, the craftsman, the new middle class to the capitalist, the public place to spend leisure time would suit classes or social stratification required. All public places that emerged during this period (Pahlavi era) and clearly mentioned in the law arising from constitutional revolution, such as hotels, cinemas, theatres, cafes, cafes, and restaurants are somehow imported and are expected to be partly carriers of the culture of origin. but the cafe, given the social burden of the term, which can be translated into a coffee shop, was the location of the new middle class, especially in the influence of European culture. the presence of women in the cafe is obvious at the separation from the coffee house, which was so conspicuous in the past decade that it may be comparable to that of another public place in density (Mehdizadeh, 2010).

Pedestrian spaces in the transition from source to destination and vice versa as the temporary stopping of pedestrians and people employed in dealing with traffic increase and social action decreased (Pozos, 2015). However, 
research in industrialized countries has faced increasing growth. Iran is faced with crisis solving problems in the course of industrial development. Therefore, in the present study, the need to study the cafes at the city level according to the location and shape of plan and distance from the employment and shopping centres, social acceptance conditions of the café, and the recognition and conformity of the interests of youth as the potential of economic growth is important.

\section{METHODS}

The introduction of appropriate action to promote better social performance as well as the introduction of the appropriate application to promote social performance, and to explain the different functions of coffee shop in different age groups and explain the kind of reaction to the environment in the café, are factors of attracting young attention in terms of internal architecture and outdoor environment. The method of research is based on the interpretation-historical and qualitative approach.

\section{RESULTS AND DISCUSSION}

\section{Coffee House in Iran}

Home coffee was not the only place to remove the fatigue and eat coffee, tea, or smoke hookah, it was also a place for community gatherings and cultural confrontation and thought. In the days when there were no mass media, the coffee centers had a lot of social, cultural, and political, significance, and it could be a center to expand intellectual understanding and current thinking as well as public morality.

In the Safavid era, with the introduction of coffee to Iran as a new drinking drink in the Islamic world and because of political stability, security, and comfort that dominated society during the Safavid period, attention to the recreational aspects of life was added. On the other hand, the need of the people of the city to a decent place to spend their free time, instead of places like the pub, all had an impact on the appearance and prosperity of the coffee houses in the cities. Coffee houses in the Safavid period were more than the upper floors of the society. It seems that during the period between Safavid and Qajar, due to the chaos and dominating the society, the coffee of the houses declined and the period passed through the interregnum.

With the advent of the Qajar dynasty, the ground was gradually formed for the prosperity of house coffee till it reached it peak in Naser alDin Shah Qajariv reign and the number of them increased. With transferring the capital to Tehran during Qajar period, Tehran was introduced as the main center for a coffee houses in Iran. Presently tea took place in coffee rather than coffee in the coffee house. The coffee houses of this period had various social, cultural, artistic, and political activities (Table 1).

In the first Pahlavi era, despite the abundance of coffee in urban and rural houses and between the way, the image of home coffee 
was declining due to modernism in society and also the negative of some of the coffee aspects of home. Its causes were the supply of opium in the coffee houses and the presence of guests in the coffee house (Maryam, 2014).

Table 1. Change and Alterations in The Cafe and The Cafe in Iran

\begin{tabular}{cl}
\hline Coffee house before the Islamic Revolution \\
\hline First period & $\begin{array}{l}\text { From the Safavid period to } \\
\text { the first }\end{array}$ \\
\hline $\begin{array}{c}\text { Second } \\
\text { period }\end{array}$ & $\begin{array}{l}\text { From Reza Shah 's reign to } \\
\text { Mohammad Reza Pahlavi } \\
\text { (1979-1979) }\end{array}$ \\
\hline Cafes and cafes after the Islamic Revolution \\
\hline First period & $\begin{array}{l}\text { The beginning of the war and } \\
\text { the fall of the pavilion and the } \\
\text { functions of the cafe and the } \\
\text { cafe (1999-1979) }\end{array}$ \\
\hline $\begin{array}{l}\text { Second } \\
\text { period }\end{array}$ & $\begin{array}{l}\text { The period of rebuilding until } \\
\text { now (2011-1390) }\end{array}$ \\
\hline
\end{tabular}

(Source: Khodabakhsh \& Yalve, 2018)

There were some political reasons. With the arrival of radio and television, and cafes and other recreational places, the coffee plantations grew gradually. In fact, during the Qajar and Pahlavi era, new reforms occurred in the structures of society, coffee houses, as well as many social institutions, were affected by political, social changes. In these days, the government adopted various policies toward the coffee house and monitored house coffee in different ways. Besides, Amy, who has been paying attention to it, is the problems that the people had, and the public dissatisfaction with the coffee house. Meanwhile, the coffee of the royal house has also been taken into consideration by researchers, if the coffee of the royal house had a story apart from the coffee of public houses as well as rules and problems (Maryam, 2014).

\section{Coffee Architecture}

The architecture of the coffee building was initially unclear. Coffee is built in every space and place without considering its former use. The physical and external space of the coffee building of old houses matched the architecture of the city and the culture of the people of the city. In Isfahan coffee house coffee was established on the northern front of the square. The porch was divided into blocks and set up in each part of the coffee house.
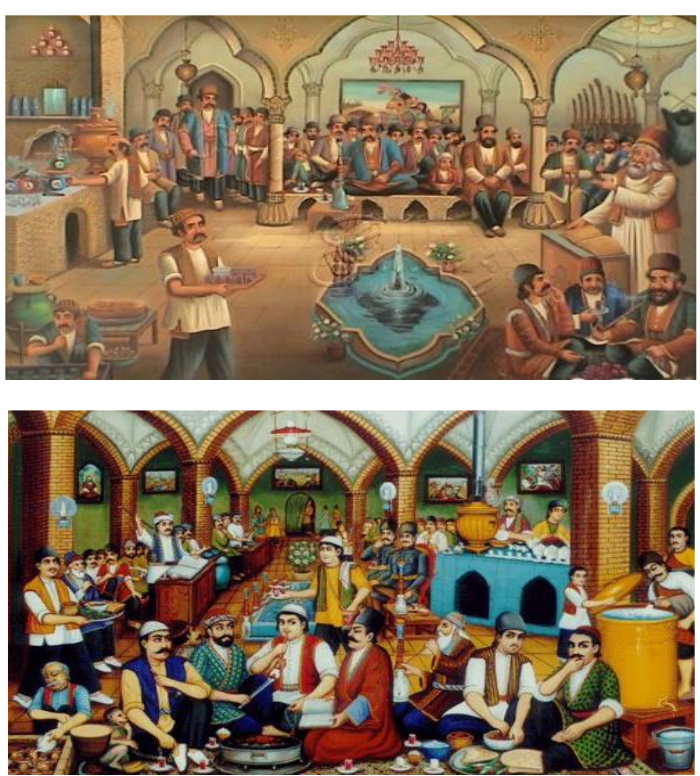

Figure 1. The Spatial Autopsy of The Traditional Coffee Shop

(Source: Salehnejad, 1398)

All the coffee was in the house, and every coffee in the house was opened. Every now and then the inner space of every coffee house was a half-circle, over which several arches were arched and walled. In the middle of the coffee 
room was a stone basin that poured water into the stream from the leachate and stone fountains surrounding it. Afterward, in order to create a suitable space with coffee use from the architecture of the house, the role of the world and architecture style of the public baths, the platform, and the terrace were used.

In Tehran, the coffee houses sat and rose, especially from the culture and the poets, the aristocracy, and the meals like broth. One example of the café, Maryam, is one of the entertainment complexes in the style and style of similar western structures on rare streets (current republic) and opened, noting that it included a hotel, cafe and confectionery. The architecture of this complex, similar to its use, was influenced by similar European and western samples, and in this eclectic architecture along the vertical axis and the use of vernacular materials such as bricks, it has been used as an extravert.

The point is that the use of it in ancient and original Iranian architecture that often has indoor and outdoor lights has been seen. The cafe still remembers the memory of Sadegh Hedayat and many of Iranian literature, intellectuals, journalists in his working memory (Khodabakhsh \& Yalve, 2018).

Rose Pozos in his thesis entitled The Coffee Shop: A City Space With Social Class Capability Between Public and Private Space (2015), "I enter a coffee shop on foot down the steps of the apartment building at the foot of New York City on the ground floor". The coffee shop called the Cats Den. Antique furniture, dark bars, low light, jazz music, and warm colors. Several young people are working together with laptops, chatting in groups of four. The impression is that there are a lot of vehicles crossing the street, and the crowds are walking. Forced to stay or leave (Pozos, 2015).

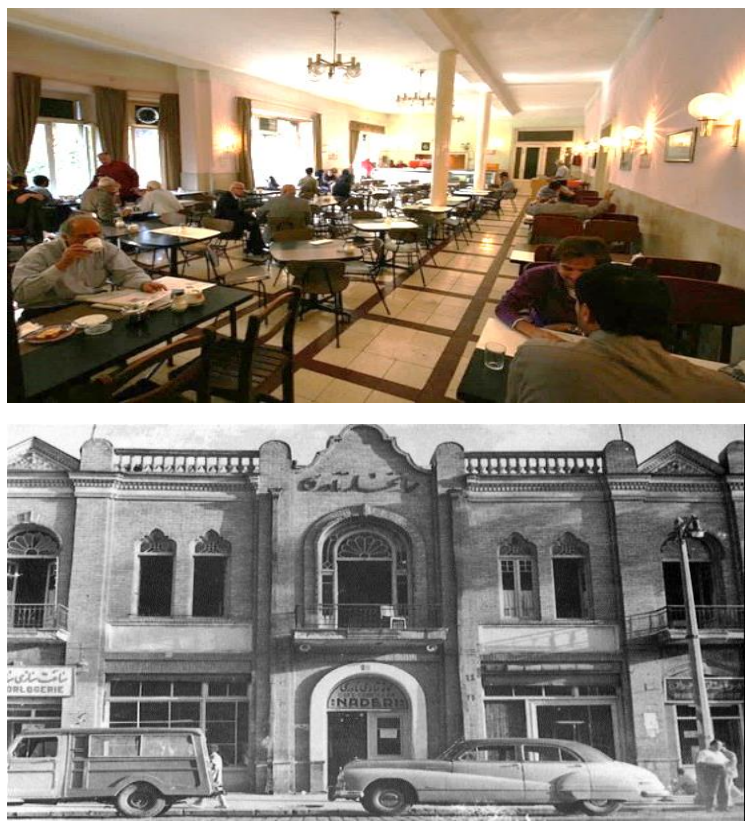

Figure 2. View and Interior Space of a Rare Cafe (Source: Irangard, 2019)

For the long months of the Cats Den, there is only the coffee shop (at the location: the author) with the closed space. In the neighbourhood, there was a lot of cafe shops, but the richness of the coffee shop has attracted the attention. Saving more security, another coffee shop in the opposite corner of the Cats Den, has been opened and has been successful in terms of dynamic and social activity. Many of them are only shopping for a cup of coffee. coffee is a way of life, and coffee developed a confident vision in the U.S., Franklin said in 2013: 
"There are a lot of people gathering in the coffee shop and gathering, because of the desire to drink coffee". Waiting outside the home for coffee or before going to work, spending time in the coffee shop for work or breakfast and Jack telling us about drug addiction, all of these are examples of coffee culture. In 2010, Pendergrast confirmed that the culture of drinking coffee was a part of the coffee shop. The coffee chain has increased by $10 \%$ annually between 2000 and 2004 (Pozos, 2015).

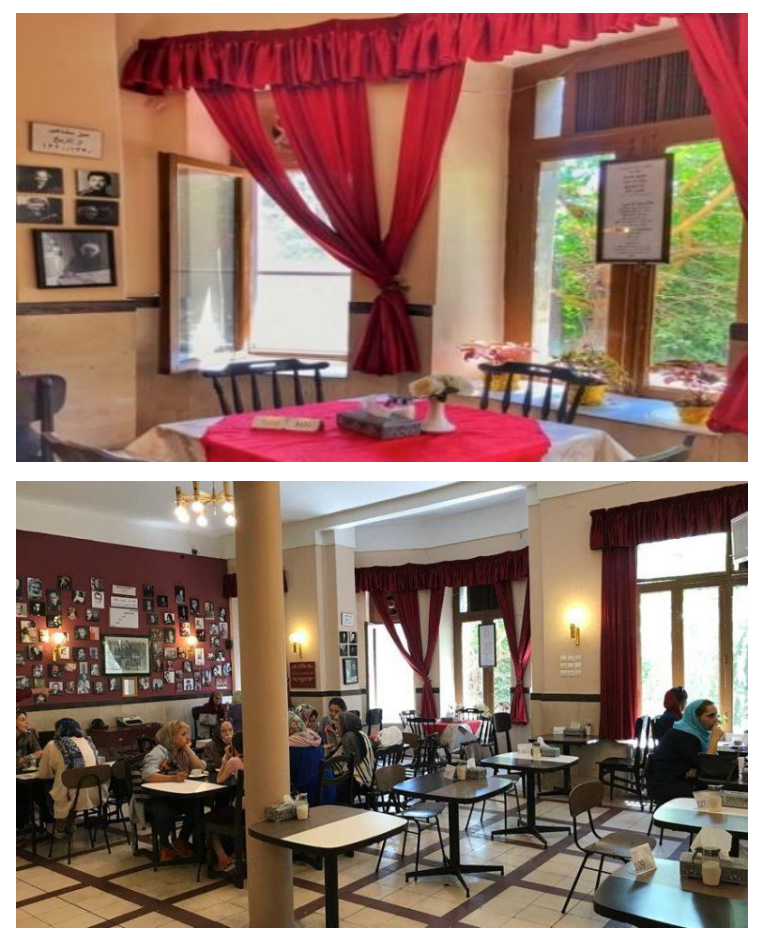

Figure 3. Decor, color and lighting, furniture layout in a rare café (Source: Irangard, 2019)

In the other part of the thesis, the need for social spaces is related to the practice of democracy discourse, and at once the coffee shops consist of such capability in contemporary urban space. It also opens the idea of the coffee shop in 1970 due to the lack of rooms and lack of living space, pointing out the need for the third space, and the tourist need for Wi-Fi possibilities (modern technology: the author) who is in the coffee shop.

It is necessary to provide artificial spaces for free work, rest and fatigue in cities. The term third place ${ }^{v}$, first used by Ray Oldenburg (1991), was used as a place to take refuge from home and work. A place that allows visits to friends, neighbors, colleagues, and even strangers.

They are typically friendly and high-quality environments that increase public attachment and increase social interaction and sense of belonging to the people. Individuals with different age and gender characteristics can meet their needs and activities by attending these social spaces. Cafes, restaurants, coffee shops, and restaurants are a good example of the same third places where Ray Oldenburg refers. It cannot be said that these places are only for young people, as they are viewed across the globe in different categories of people in a different age group because the presence of equal conditions in the use of people is the requirement for this place (Khodabakhsh \& Yalve, 2018).

Asaf Bar-Tura in 2011, said the establishment of the cafes began outside the political resistance space. In 2005, Cowan stated that the basis of the formation of tavern cafes was for the publication of news and newspapers and a wine shop. The structure of the coffeehouse was for business activities and the pursuit of activities. The coffee house is a social 
space and is not normal in terms of men and women, and the majority are men and not in the correct family structure. Most people talk about political and social changes, trying to turn their opinions into law, while in Europe coffee houses have more social acceptance (Pozos, 2015).

Women from the elite social class have no desire to repeat the use of the coffee shop, and from the lower social class simply enter the centre of cafes. a group of women is interested in speculation in the political discourse of these places. The consensus is that events are not related to the 17 th and eighteenth centuries. Women are more likely to be involved in providing coffee for men (Pozos, 2015).

A brief historical glance can be said that spaces and places are generally created to meet the needs of biological and cultural needs. they also respond to the needs of socializing, said the cafe. restaurants and meals are suited to meet the needs of life, but the cafe is essentially based on intellectual needs and social interaction. a lack of public sphere in society requires a critical dialogue on which a part of this need is met. For example, in the thirty-forty decade of our decade, our solar system is facing the shrinking of public space and cafe development (Ghaneei, 2013).

It must be acknowledged that attendance in the cafe is proportional to cultural capital. Culture, education, and thinking about the persistence of life in the cafe. this cultural capital is of course education and wisdom and is the most cultural capital of human sciences and arts. most of the audience in the cafe is philosophy criticism, literary criticism, and art, and it includes higher demographic data. therefore, more than human capital should speak of intellectual capital. Students with a tendency to humanities can also be found among the students of engineering who also describe Sohrab Sepehri or Sartre, as well as the contemporary literature and art of Iran and the world. you can find people of middle-class culture, poets, painters, music, writer, and translator. but to find businessmen, privatesector workers went to Iranian restaurants and in particular. If you are looking for people from lower or middle-middle classes, find most of them in coffee houses, parks, and regular dining rooms.

The conflict, competitions, exchanges, and cultural imagery have made Iran's culture very diverse. Iranian youth have been affected by the macro-cultural changes in national and national socio-cultural changes as well as affected by their different social positions in light of the rigorous life light that is essential to understanding cultural developments. one way to recognize these styles of life is the study of certain haunts which have been formed in Iran after the war. They play an important role in creating these cultures as well as the formation of certain social relations and lifestyles (Shalchi, 2007).

A coffee shop is one of the manifestations of Iranian youth after the war. The coffee shop is a new thing in Iran, unlike some ideas that 
continue to see this phenomenon, although some of the features and features of the former cafes are similar to coffee shops, and even some of the society still has the same look at cafes (Shalchi, 2007).

As the term class is applied to a group of individuals in the same class status, the rank of rank also includes those who have the same dignity in the system, but one class does not own the formation of a community per se. There are, however, a form of community, as opposed to the classes. therefore, members of a high-rank group are correlated with each other (Shalchi, 2007).

The Importance of Designing The Local

\section{Decoration of The Coffee Shop}

All of the people who come into the coffee shop have different views of the ambiguity and fluid of space. On the contrary, the restaurant, which has a single decoration, offers the use of diversity in the coffee shop, and people have the freedom to work and sit on the back of their laptop or book reading. The internal concept and the colors of the wall, table, and drawing of chairs, lighting, and music create an index for selecting the client from the coffee shop. Cost reduction is one of the determinants of customer satisfaction.

The coffee shop interior decoration, the time to stop the audience, color, and music determine your mental behaviour is staying and leaving space. Pastel colors, soft music, wooden furniture, spring bench, or comfort armchairs will lead to the retention of the audience for longer periods of time. Red and yellow are stimulating and exciting, which is why it is used in the design of the cafe. High lighting has a negative effect on the client, making it feel comfortable while eating.

Human environment communication is the process that humans adopt from surrounding environmental factors. They are imposed on different degrees of human comfort in different situations. For the interior design of a great, great coffee shop you have to compare these factors. Cafes such as restaurants, bars, and hotels depend on the satisfaction of the audience. The satisfaction of individuals is not only related to food but also the space and conditions of the environment. Some of these variables are:

\section{A. Homeyness}

As it comes from the term name, it consists of a lasting feeling at home. It includes props like decoration, beauty, comfort, emotion, and contact with the environment. The cafes need to create a comfortable degree of convenience that matches your audience's comfortable home conditions. It can also refer to the wood types used in the decor, lamps and their installation locations, the convenience of furniture that customers sit on (Anon, 2019). 

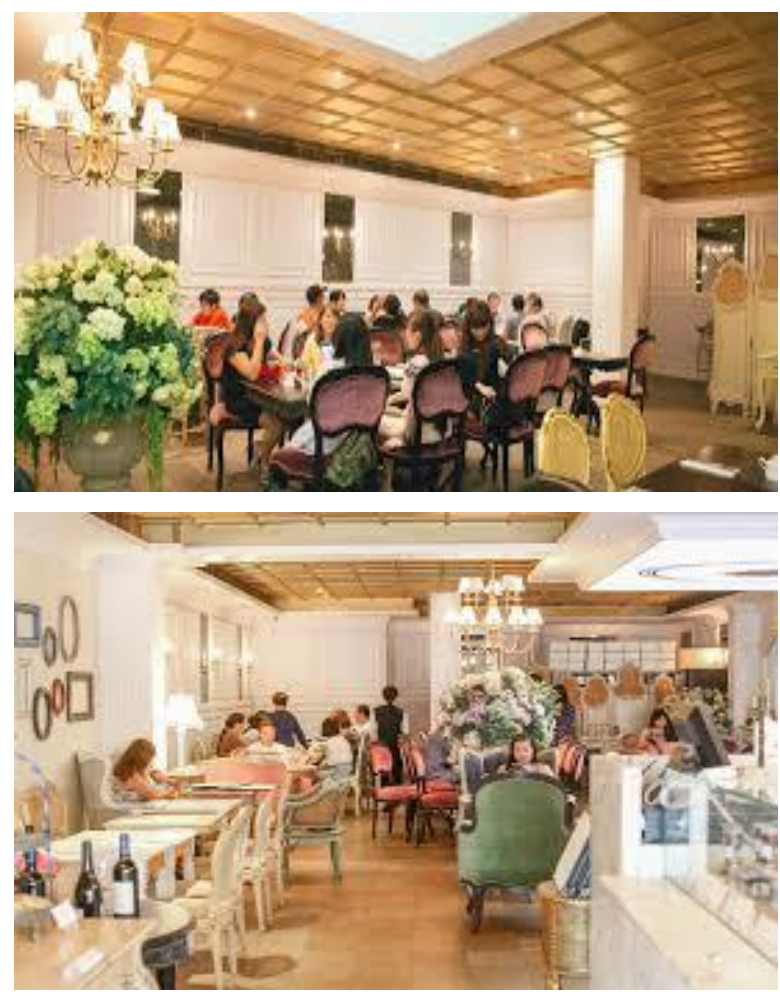

Figure 4. Importance of Depending on The Importance of The Color Dependency and The Furniture and Furniture Styles and Lighting in Social Participation

(Source: Anon, 2019)

\section{B. Visual attractiveness}

Visual attractiveness is a balance between five senses of emotion, position and activation. So, none of the cafe elements should be powerful. The process is composed of four factors (color, light, smell, and sound). When the correct composition is created, a mixed sound impression is created for the audience at the cafe.

\section{Population density}

This process involves the measure of population psychology. Optimizing the interior design is based on the feeling of personal averages. This process includes the order of space between the two tables, the number of orders based on the mess.

\section{Private privacy}

The coffee's hostess has to pay attention to people who are willing to work together and people who are reluctant to work. So, it is important to achieve the right of privacy in the location of internal design elements and create a balance for both the audience, and create balance between tool, music voice and internal decorations, varying degrees of privacy demand. There is minimal design in the right direction of designing the coffee, the existence of benches and group tables, and length to set up the seating table at the table for people who are not interested in the social space. The combination of privacy in the section relates to the hustle and bustle of the population.

\section{The Physical Indices of Architectural Space,} Social Index, Interest in The Cafe and Coffee Shop

Reviewing the contents of the history of cafes and study samples in Iran and modern east, America, and East Asia and studying the opinions of cultural and cultural figures in explaining the social space and the architecture of coffee shop and coffee shop are briefly mentioned in the following Table 2 and Table 3.

\section{An Example of a Coffee Shop Project Made in Iran}

One of the most important issues in the design of the coffee shop is drawing attention to the terms of the culture of region and attention to the privacy and privacy of the most important issues in Iran. Furniture layout and user space sharing are influenced by the comfort of people. The importance of attachment of social 
participation is attention to colour and decor and sense of place belonging to architectural space factors. The reason for the selection of samples is variation in geographical location, design style, space function, space use variation, attention to decoration, and colour (Table 4 and Table 5).

\section{Coffee Shop Dimensions}

Due to the increase in the cost of housing and the increase of urban population, the dimensions of plan residential units decrease and the need for social interaction spaces to spend leisure time increases. The importance of the third place to reduce work stress and distance has led to social interaction and the importance of the third-place increases its importance. Studies show that distance and closeness to the use of administrative, commercial, educational spaces are effective in the selection of decorations and the number of audiences.

Coffee shop dimensions play an important role in providing local lighting and the percentage of wall transparency overlooking the sidewalk and dimension and the number of light walls have high importance. Due to the analysis of the coffee shop model, the arrangement of furniture in the proximity of the clear wall to dominate urban landscapes and the sight of pedestrians and riders is of importance to the audience. Selection of the regioselectivity of the audience in plan varies according to the age group. At the age of 40 , they are interested in selecting the location of furniture outside the coffee shop, and at a younger age, especially the 17-25-year-old age group, they are calling for use of the study area and the four-member working tables with wireless and wireless technologies. Given the interest of the young population in social participation, attention to the taste of young people in decoration and colour can be clearly investigated.

\section{CONCLUSION}

\section{Coffee House in Iran}

As say before, coffee house has important role in Safavid, Qajar and Pahlavi eras. Architecture of coffee house that first have lower floor then, change to ground floor in Pahlavi. People use of coffee house to political role and exchange information same as newspaper every day and next era use it for display poem and history define of "Shahnameh Ferdowsi". Today use it for short rest of urban work circulation, young people activate same as see each other, laptop work, café drink. As you see, exchange step to step European and Americans coffee shop method.

An other hand, can name exchange traditional method to modern. As I say before, coffee house using for upper level of society in Safavid era, and next era The middle classes of society exchanged.

The important point, attitude in political and public work activity and culture and development of education of academic for young population effect to method of use it. By reviewing historical and historical studies of 
architects and sociologists about the importance of spaces with the application of social interaction and recognition of the number of young people from spaces for urban temporal relaxation, indexes of visual interest, privacy, population, and urban environment are more important in the selection of spatial and temporal choice. The privacy discussion of the standard spacing and the type of table layout and even the location of private sessions with the measure of clear and short partitions is investigated. also, acoustic space and attention to the type of addressee use, such as individual study or social work environment, must be adopted.

In the discussion of visual appeal, lighting, colour, smell, and sound are important. The type of light selection is different in natural and artificial light, and it takes many different measures even when using the day. The daylight is the focus of the audience and the artificial yellow light is required at the top priority to attract the audience. according to the statistical population, the majority of young people with full-time employment have approved the need to expand social interaction spaces. The number of referrals is weekly, and the main reasons for the youth's visit to the coffee shop are social interactions. The duration of the elapsed time is in the week and the amount of expenditure on the average level. Choosing the right place of coffee shop with respect to the main transit and traffic congestion and ride the importance of it adds to its importance and social role (Table 7 and Table 8).

In the study of drawing of four examples of coffee shops in Iran and study of the site and effective distances of urban social interaction and the importance of spatial and spatial dependency on the results of the positive and negative importance of the following table (Table 9). For the transparency of the coffee shop and design points and comparison of the selected style in the eastern countries, two examples of the coffee shop implemented in the Japanese country have been selected and studied (Table 6) .

I try to write and study eastern country idea about coffee shop design, material, colours, location, style of architecture, face to environment, population and attraction. Culture and young people effect to design and you see as long of essay, step to step revolution of design method and attention. I select to Japan coffee shop building because of the nearest sustainable development and environment attention and development country in Asia. In Table 9 try to executive result of Table 7 and Table 8 that compared to positive points in Homeyness, visual attraction, population partnership, privacy and plan of all examples in Table 4 and Table 5. 
Table 2. Comparison of The Architectural Space Index at The Coffee Shop and The Coffee Shop

\begin{tabular}{cll}
\hline \multicolumn{1}{c}{ No. Coffee house } & \multicolumn{1}{c}{ Coffee Shop } \\
\hline 1 & The entrance to a few steps & A user on the ground floor \\
\hline 2 & $\begin{array}{l}\text { The adaptation of the physical and outer } \\
\text { space of the coffee shop }\end{array}$ & The transparent wall of the facade \\
\hline 3 & twilight & Light shadow Space \\
\hline 4 & Sharing of internal Ivan & Common Space \\
\hline 5 & Relationships between multi coffee shop & Independent \\
\hline 6 & The entrance to the street & Nearest sides in the street \\
\hline 7 & Middle Rock Basin & - \\
\hline 8 & Traditional decorations & Warm and modern colour decorations \\
\hline 9 & The furniture of the traditional throne & Antique furniture \\
& and the semicircular platform & \\
\hline 10 & Lecture, reading Shahnameh, presents & Music and jazz \\
\hline 11 & Flat layout & Arrangement of two - and - four - person tables \\
\hline
\end{tabular}

Table 3. Comparison of Social Index

\begin{tabular}{rll}
\hline No. & \multicolumn{1}{c}{ Coffee house } & Coffee Shop \\
\hline 1 & Drinking Tea & Coffee drink \\
\hline 2 & The wine shop and the intellectual space & Romantic space \\
\hline 3 & Political and social beliefs & Democracy talk \\
\hline 4 & Print the News and the News & Chat \\
\hline 5 & Commercial activity & Work participation activity \\
\hline 6 & The participation of the majority of men & Male and female involvement \\
\hline 7 & The business aims of women & Social intellectual exchange goals \\
\hline 8 & Mean age 30, 40 and over & Age mean between 17 and 25 years \\
\hline 9 & Multi-Seat Cafes & Four-member groups \\
\hline 10 & Literary space & Two-person emotional space \\
\hline 11 & Correspondence and update & Wireless technology and laptop \\
\hline 12 & The different cortex & Waiting for friends and friends \\
\hline 13 & Free career participation & Student participation \\
\hline 14 & Men of letters & Art, cinema, theatre \\
\hline 15 & Drinking Tea & Coffee drink \\
\hline
\end{tabular}


Table 4. Tehran-Shiraz City, Mashhad-Shiraz City and Tehran

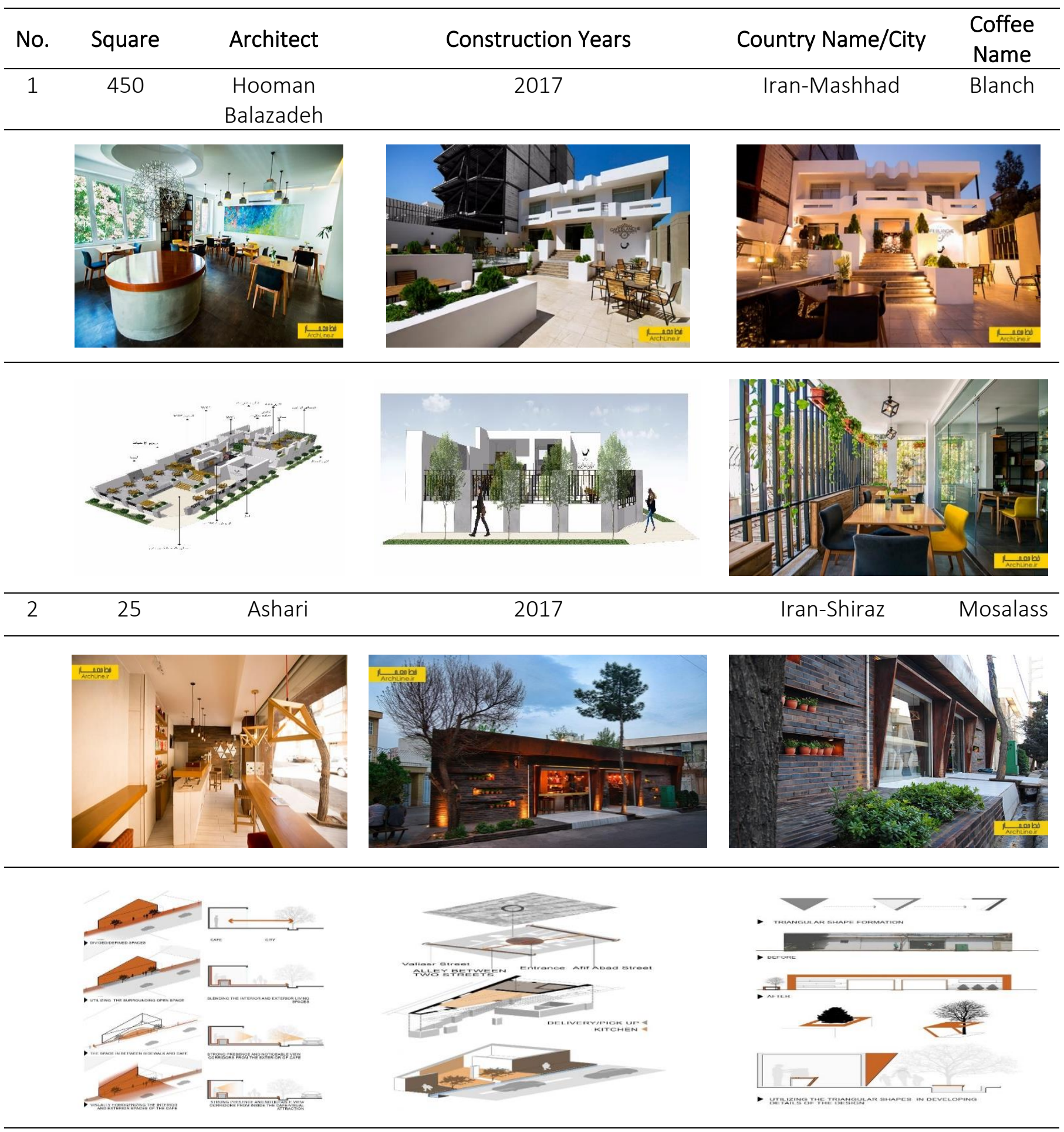


Table 5. Tehran-Shiraz City, Mashhad-Shiraz City and Tehran

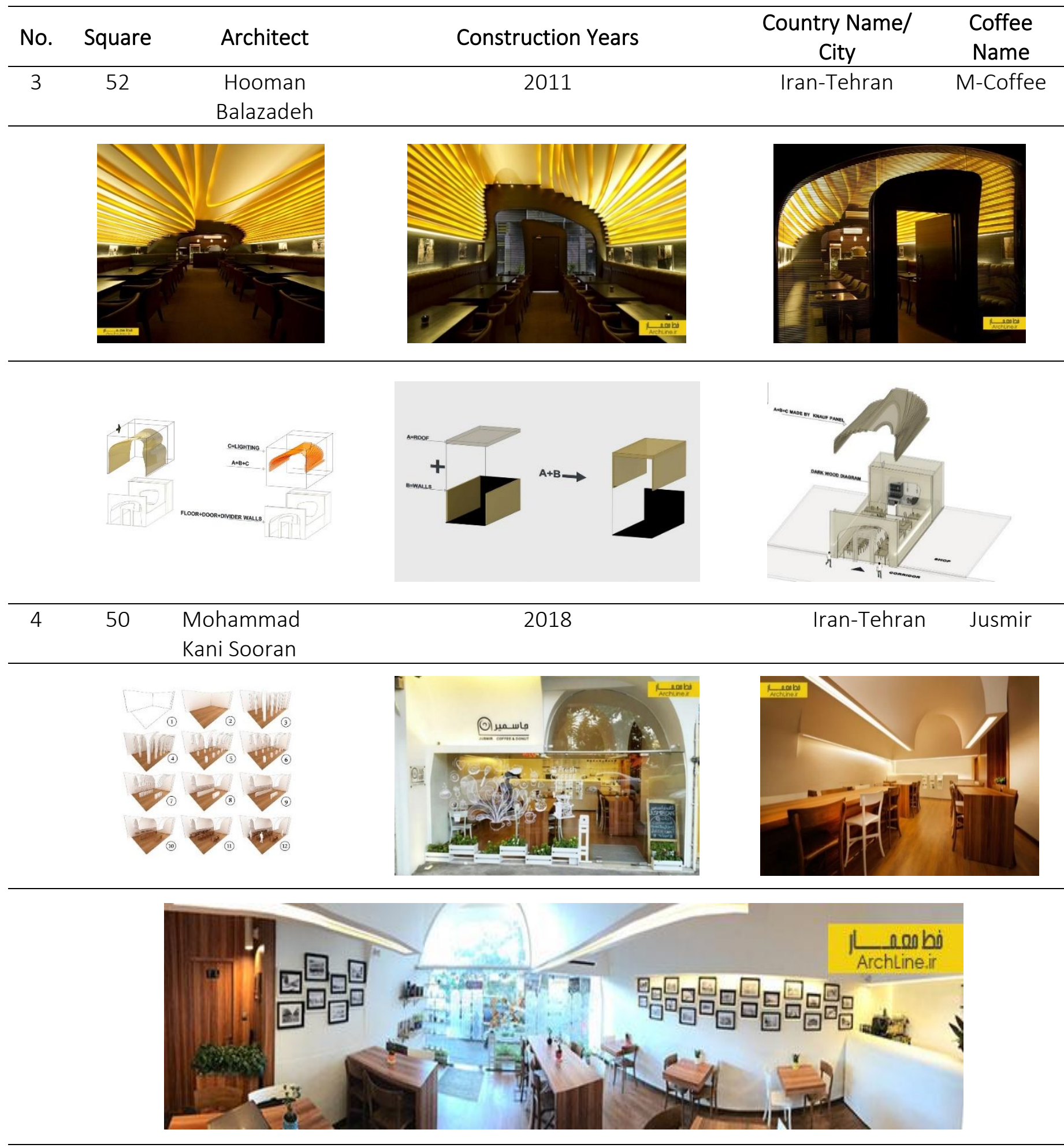

(Source: Abdel, 2020) 
Table 6. A Sample of The Coffee Shop Created in Japan

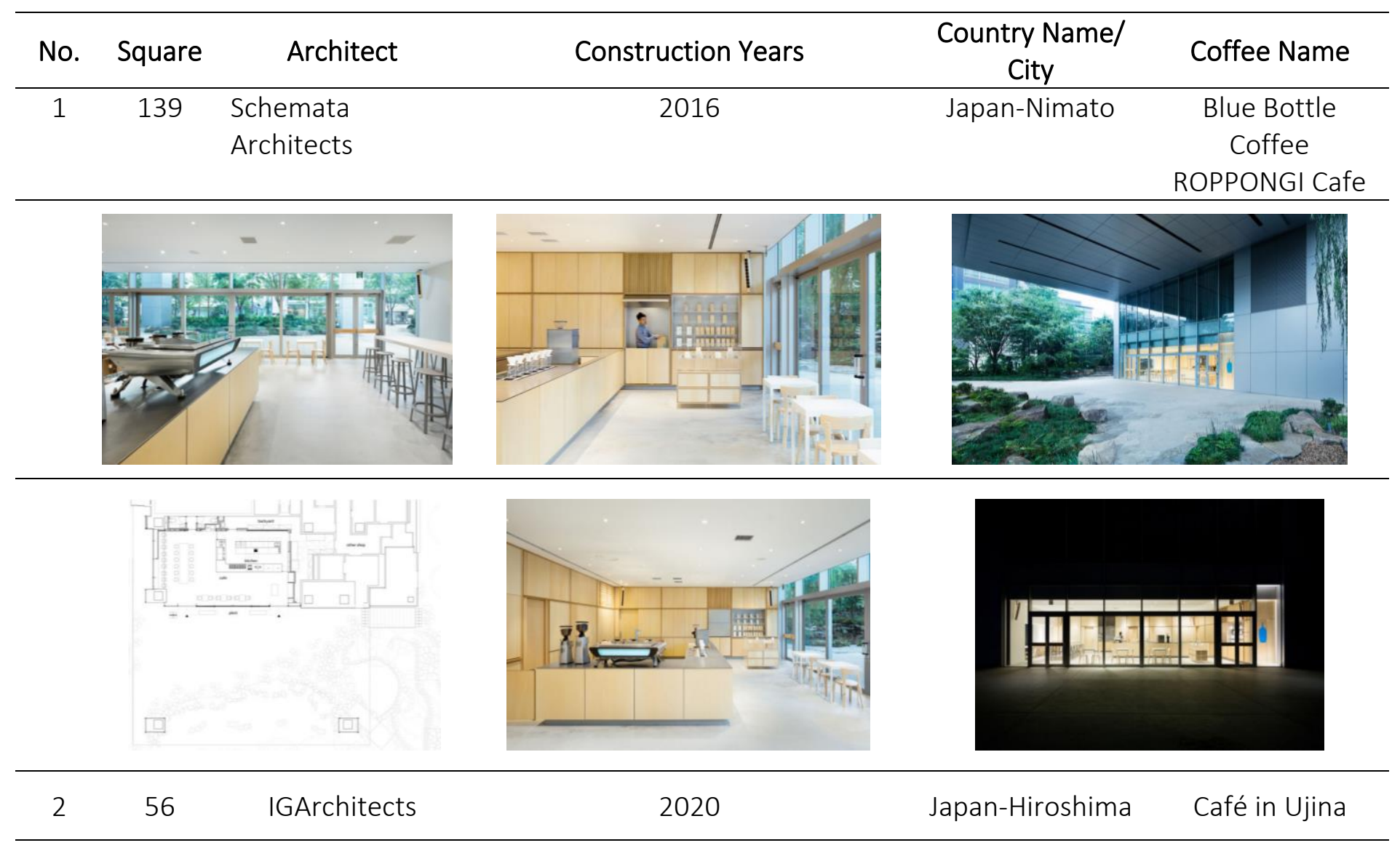
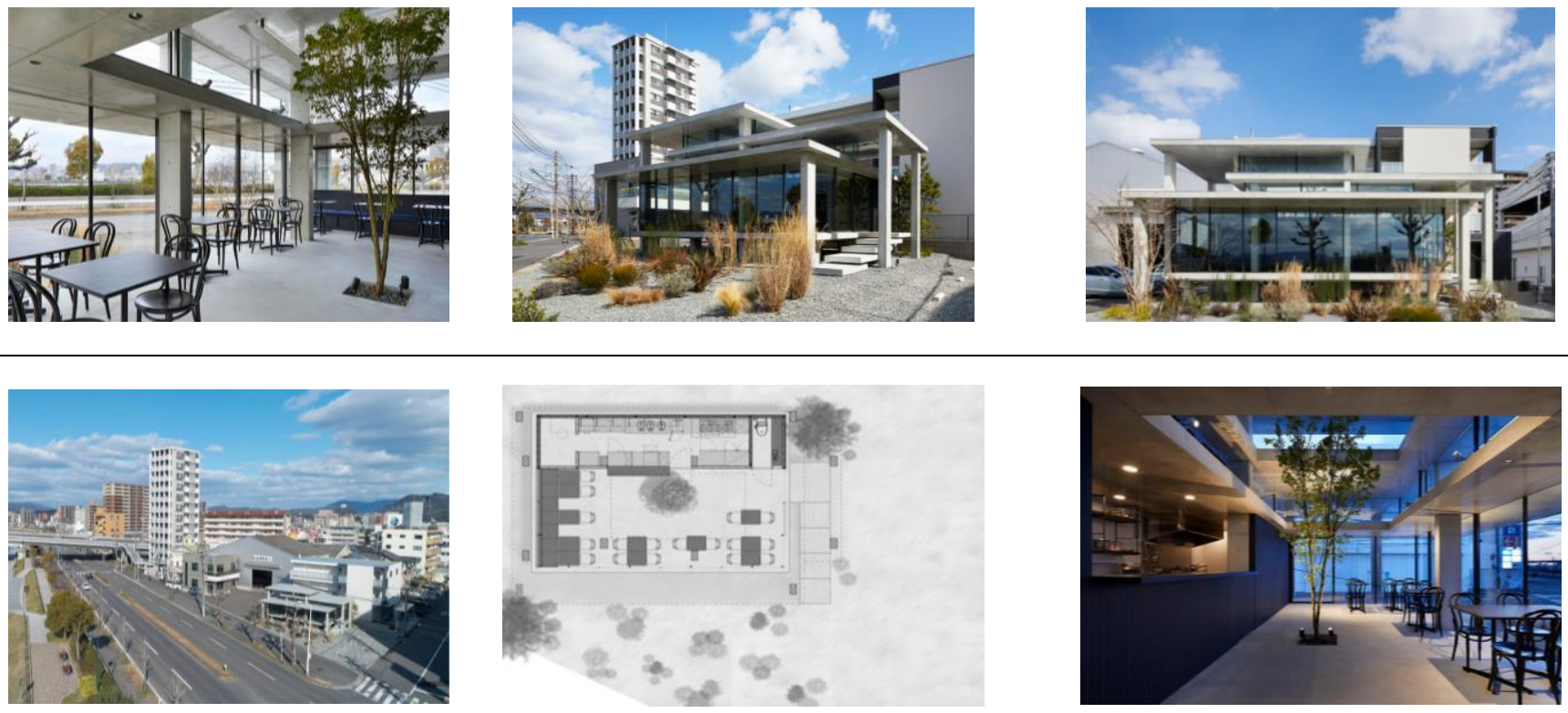

(Source: Ota, 2016) 
Table 7. Criteria for Comparing The Social Index and Acceptance of The Audience in The Coffee Shop (Author's View)

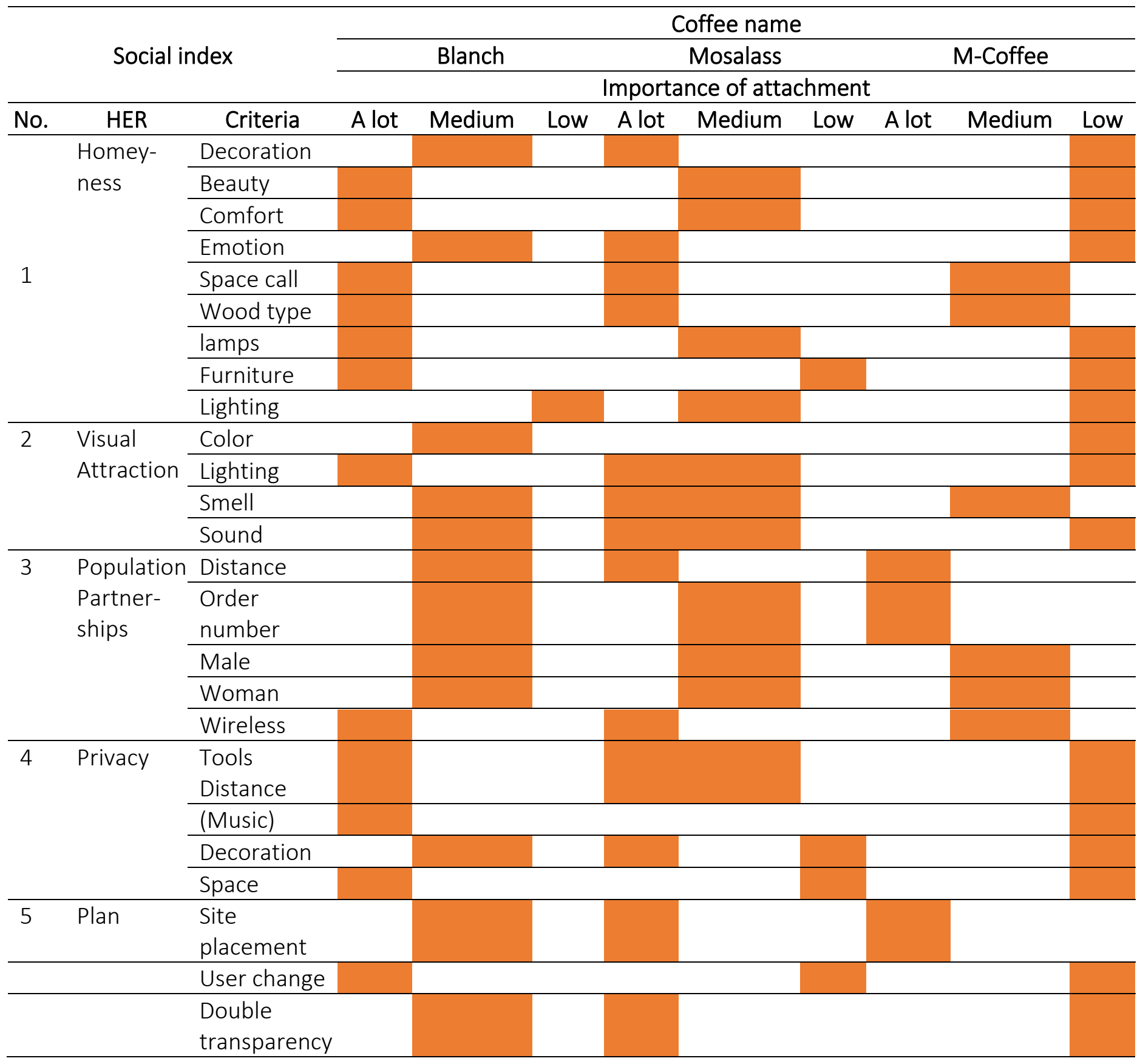


Table 8. Criteria for Comparing The Social Index and Acceptance of The Audience in The Coffee Shop (Author's View)

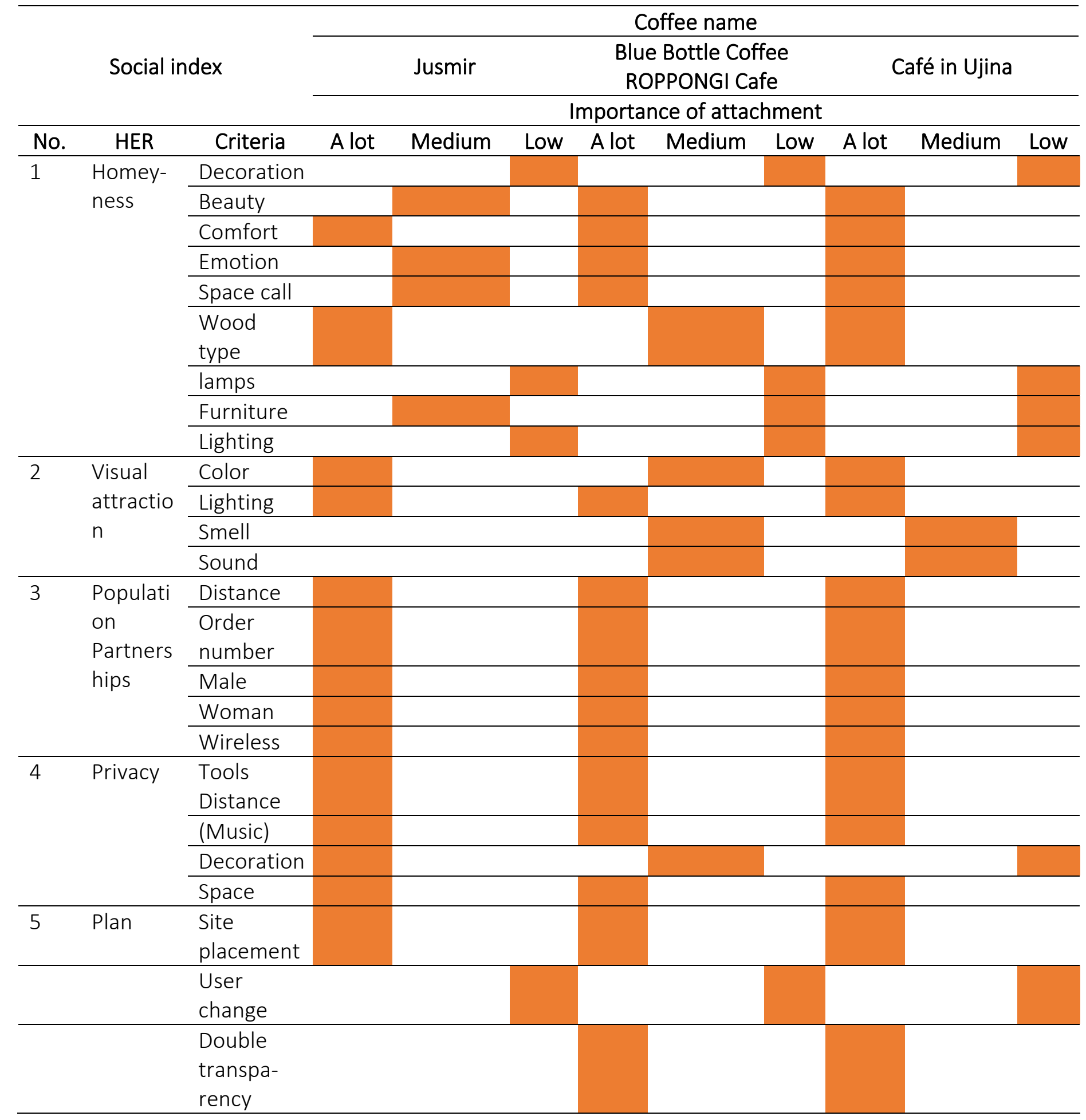


Table 9. The Results of The Positive and Negative Points of The Study Were Studied

\begin{tabular}{lll}
\hline No. $\begin{array}{c}\text { Coffee Shop } \\
\text { Name }\end{array}$ & \multicolumn{1}{c}{ Positive Point } \\
\hline $1 \quad$ Blanch & $\begin{array}{l}\text { The privacy gap in the space layout is well } \\
\text { observed. }\end{array}$ \\
& \\
& $\begin{array}{l}\text { due to the change of residential land to } \\
\text { the coffee shop, space layout and } \\
\text { furniture is well observed }\end{array}$
\end{tabular}

\section{Negative Point}

due to the importance of home city environment and visual appeal on the high and medium level, and due to the location of the plan, the plan of community participation is at a relatively distant distance from the commercial and educational centres.

the importance of social acceptability has diminished the importance of social acceptability, in the proximity of the main street and the lack of transparent sidewall of all glass in the main facade and the wall of the common wall of the site.

2 Mosalass The transparency of the facade and the dominance of the audience on the city and the city are excellent.

The small dimensions of space in terms of decoration and space are due to lack of

the appropriate placement of the plan site in the range of middle distance is educational and trade centers.

$\begin{array}{ll} & \text { the appropriate placement of the plan site } \\ & \text { in the range of middle distance is } \\ & \text { educational and trade centers. }\end{array}$
services centers are suitable. respect for privacy and social engagement.

$4 \quad$ Jusmir in addition to location of the plan and the appropriate distance from urban service centers, the home city environment has an average importance but has increased the number of social participations.

Due to the small dimensions of plan, the The roof is very simple and decor is very privacy factors are well observed

Visual attractiveness and environmental factors of home and privacy are of low importance.

There is no division of privacy space and furniture layout.

5 Blue Bottle Given the decorand setup of thelamp, the There is no furniture layout in the four Coffee importance of social participation and membergroups. privacy is added.

The clear sidewall is appropriate, and site The library and library are not available. placement is appropriate.

The dimensions of the grand plan and Privacy in privacy is not observed. minimal design style are minimal.

$6 \quad$ Café in Ujin the transparent wall and the space and Lighting and decoration is of low color dependency and social participation importance. are of high importance.

The dimensions of the great plan and the There is no privacy space sharing for green space are in the center of the plan. discourse and meetings.

There is a furniture layout outside the The library and library are not available. cafe.

This is a minimal design style. 


\section{REFERENCES}

Abdel, H. (2020). Café In Ujina / Igarchitects. Retrieved from https://www.archdaily.com/ 936601/Cafe-In-Ujina-Igarchitects?Ad_Sour $c e=$ Search\&Ad_Medium=Search_Result_Pr ojects

Anon. (2019). Cafe Interior Design: Top Things to Keep in Mind While Designing a Cafe. Retrieved from https://www.posis t.com/restaurant-times/singapore/cafe-inte rior-design-tips.html

Ghaneei, M. A. (2013, May 1). From The Classic Form of Cafes [Personal Interview].

Irangard, E. (2019). The Rare Cafe in Tehran: Cracked Memories in The Nostalgic Resort Of. Retrieved from https://www.nabro.ir/nade ri-cafe/

Khodabakhsh, S. \& Yalve, S. (2018). Comparative Study of Social Function - The Place of Contemporary Iranian Cafes and Cafes. Legacy of Time, 8-18.

Maryam, S. (2014). Reviewing The Cognitive Document of The Coffee Houses from The

\footnotetext{
i The Safavid dynasty was one of the most significant ruling dynasties of Iran from 1501 to 1736 . The Safavid dynasty had its origin in the Safavid order of Sufism, which was established in the city of Ardabil in the Iranian Azerbaijan region.

ii Abbas the Great or Abbas I of Persia was the 5th Safavid Shah of Iran, and is generally considered as one of the greatest rulers of Persian history and the Safavid dynasty. He was the third son of Shah Mohammad Khodabanda.

iii The Qajar dynasty was an Iranian royal dynasty of Turkic origin, specifically from the Qajar tribe, ruling over Iran from 1789 to 1925. The Qajar family took full control of Iran in 1794, deposing
}

Naseri Period to The End of The First Pahlavi.

Tehran: Faculty of Literature and Humanities. Mehdizadeh, J. (2010). Cafes, Parallel Fields and The Strengthening of The Public Sphere. Retrieved from https://donya-e-eqtesa d.com/

Ota, T. (2016). Coffee Shop, Interiors Architecture. Retrieved from https://www.archdaily.com /796596/Blue-Bottle-Coffee-Roppongi-Cafe -Schemata-Architects?Ad_Source=Search\& Ad_Medium=Search_Result_All

Pozos, R. K. (2015). Coffee Shops: Exploring Urban Sociability and Social Class in The Intersection of Public and Private Space [Thesis]. Department of Anthropology Stanford University, United States. Salehnejad, N. (1398). History Of Coffee in Iran. Retrieved from https://www.kojaro.com/ 2016/5/26/119337/Teahouse--History-Iran/ Shalchi, V. (2007). The Lifestyle of The Young People. History of Cultural Research, 93-115.

Lotf 'Ali Khan, the last Shah of the Zand dynasty, and re-asserted Iranian sovereignty over large parts of the Caucasus.

iv Naser al-Din Shah Qajar was the Shah of Qajar Iran from 5 September 1848 to 1 May 1896 when he was assassinated. He was the son of Mohammad Shah Qajar and Malek Jahān Khānom and the third longest reigning monarch in Iranian history after Shapur II of the Sassanid dynasty and Tahmasp I of the Safavid Dynasty.

$\checkmark$ The third place is an area where urban sociologist Ray Oldenburg defines it as a shelter in front of home or workplace; where people can visit regularly and interact with friends, neighbours, colleagues, and even strangers. 